\title{
Empowering Students to Articulate into Second Year of a Nursing Degree Programme
}

\author{
Joan Irwin, Senior Lecturer \\ University of the West of Scotland (UWS) \\ Paisley, Scotland \\ Joan.irwin@uws.ac.uk
}

\author{
Louise Johnston, Lecturer- Adult Nursing \\ University of the West of Scotland (UWS) \\ Ayr, Scotland \\ Louise.johnston@uws.ac.uk
}

\begin{abstract}
As an institution the University of the West of Scotland (UWS), School of Health, Nursing \& Midwifery has endeavoured to enhance the articulation of nursing students from Further Education (FE to Higher Education (HE) with involvement \& support of local Health Boards. This area of work also recognises that the Nursing \& Midwifery Council (2010) require HE Establishments to recognise students prior learning to facilitate career pathways. Students articulating into second year need to feel empowered to succeed. Long standing partnership working with local colleges and the work of the South West Articulation Hub saw the development of a module to facilitate some students joining the degree programmes in second year. The module provided by UWS over the summer time enables those selected from their HNC year to commence early engagement with UWS. The empowerment process then begins socially and academically to facilitate the transition from $\mathrm{FE}$ student to HE students equipped with the skills and practice hours to succeed in second year.

This presentation will discuss the module and its role in empowering the students and highlight the evaluations of the first group of students through the module. The findings will suggest the empowerment process is vital to student's engagement and success.
\end{abstract}

Keywords- empowerment, articulation, student transition.

\section{Introduction}

Following the Project 2000 proposals (UKCC 1986) nurse education changed fundamentally and moved into Higher Education Institutions (HEI's) from traditional schools of nursing. The Nursing and Midwifery Council (NMC 2004) stipulate the standards of proficiency for pre-registration nurse education. These standards also incorporate a requirement for HEI's to acknowledge students prior learning and this has contributed to a widening of access to pre-registration nursing courses. This widening access has allowed students to enter in greater numbers and has increased the diversity of the student nurse population (McCarey et al. 2007).
Over the last number of years the widening of access to Further and Higher Education in Scotland has also been encouraged by various policy initiatives (Scottish Executive 1999, Scottish Executive 2003). The Scottish Credit and Qualifications Framework (SCQF), established in 2001 amalgamated the main qualification frameworks creating a single structure with an aim to "assist people of all ages and circumstances to access appropriate education and training over their lifetime to fulfil their personal, social and economic potential" (SCQF 2001, p.1) further supporting lifelong learning in Scotland.

The development of articulation routes into Higher Education Institutions has become key to facilitate the creation of additional pathways into university. (Scottish Funding Council 2011). Articulation is the process whereby a previous qualification allows a student to enter directly into second or third year of a university degree programme. Gallacher (2006) suggests that these articulation pathways require close partnership working between Further and Higher Education Institutions to adequately prepare students for advanced entry into university. This facilitation of career pathways endorses the Scottish Government's undertaking to promote the creation of adaptable articulation routes (Scottish Government 2011).

This paper explores the long standing partnership working with local colleges, Health Boards and the South West Articulation Hub in the development of a model to facilitate the articulation of a number of students into second year of the University of the West of Scotland (UWS) undergraduate nursing degree programme.

\section{Articulation}

As an institution UWS School of Health, Nursing \& Midwifery (HNM) has endeavoured to enhance the articulation of nursing students from FE to HE with involvement of local Health Boards. UWS although a modern university has a long standing 
philosophy of widening participation and providing local education (UWS, 2008)

Robbins (1963) suggested that Higher Education had four aims: (1) instruction in skills; (2) promoting the general powers of the mind; (3) the advancement of learning and (4) the transmission of a common culture and common standards of citizenship. Robbins (1963) therefore provided the basis for an expanding higher education system which encouraged wider participation and accepted diversity of missions between institutions. The more recent Scottish Government report (2011) sets the educational context in more modern terms by suggesting that Higher Education in Scotland should be a civilising force making key contributions to the economic success of the country.

The vision of UWS is that it will have "transformational influence on the economic, social \& cultural development" within its local area and beyond by providing "high quality, inclusive higher education and innovative and useful research" (UWS 2008, p.2). UWS (2008) stated in its strategic plan (2008-2015) that it aims to be uniquely responsive to partnership working and new demands made on education. This module that has been developed is an exemplar of such partnership working through articulation.

Since 2007 the Scottish Funding Council (SFC) designated articulation hubs have been working in local areas and at national level with the common aim of articulating students into years 2 / 3 of degree programmes (South West Articulation Hub, 2009). Prior to this within UWS a career structure existed for local health board employees (as care assistants) to remain "employed" whilst undertaking the three year nurse education programme. This was by attending a local FE college in year 1 and articulating into UWS for years 2 and 3 , whilst remaining on their salary. Gradually however with the changes in economic climate and funding for this initiative the places for this are extremely limited to one local area. However, in working in long standing partnerships with local FE colleges and Health Boards UWS recognised the need for such work to continue through new articulation opportunities.

Thus the South West Articulation Hub (SWAH, 2009) was set up and sets out its aims in its "Forward plan" (2008-2013). Health Nursing \& Midwifery (HNM) was part of the SWAH but also had to work within the constraints of the Nursing \& Midwifery Council for entry of students to the national register (NMC 2010). A small team within HNM bid through SWAH for funding for a project which was completed 2010/11. This involved inviting students from local HNC FE courses to come into UWS twice during their HNC year and link in with UWS environment, staff and students. The evaluations from this work and meetings with local FE colleges from the SWAH formed the basis for discussions for a new learner journey through articulation.

Students commence HNC with local FE colleges and are then selected by UWS for year 2 Nursing Degree (Adult or Mental Health). They then complete a bespoke module (Extended Practice Learning Experience - PLE) over the summer months prior to commencement at UWS. The outcomes of their HNC year and UWS year 1 are mapped together so that any potential deficit can be addressed. It is important that the students are prepared with the knowledge and skills required to commence their higher education (Cree et al, 2009)

\section{Transition}

For students to become properly integrated in their new university environment they must complete three steps: separation, transition and incorporation (Tinto 1987 cited in Whittaker 2008). McInnis et al (2000) advocate that students experience four main forms of transition: personal and social; geographic; administrative and academic.

According to Harvey et al. (2006) students require assistance to settle into university and to become independent learners. The growth of Higher Education and the diversity of the student population have brought about an increased need to support this heterogeneous student group (Harvey et al. 2006). The feeling of fitting in within Higher Education and the establishment of friendships has been advocated as being vital in assisting students' personal and social transition into first year (Yorke and Longden, 2007).

Support has been highlighted as being crucial in the assistance of integration into higher education. Support can come from various sectors including family; friends; peers; tutors as well as formal student support organisations (Steele et al. 2005). Woodfield (2002) indicates that the friendship support networks that students establish provide a vital support system as they experience the fluctuating highs and lows of student life.

Geographical transition issues are linked to the impact large spread out campuses have on students (Whittaker 2008). Cree et al. (2009) advocate that large universities can be overwhelming for students as can large classes, with many students who enter higher education being exposed to large class sizes for the first time. Thomas and Hixenbaugh (2006) purport that large classes can have an effect on both traditional and non- 
traditional students and can lead to a decrease in the personalised approach to learning.

Administrative transition involves issues including enrolment, access to information networks and academic staff (Whittaker 2008). Universities now use information technology for many of their administrative purposes (Haigh 2004). Peyrovi et al (2005) advocate that students should be encouraged to use the support of Information Technology (IT) departments, tutors and peers to become more familiar with the institution's IT applications and environment. Fleming and McKee (2005) indicate the importance of including IT skills support for all IT competence levels and also endorses the inclusion of IT skills support in induction programmes.

The political drivers which have led to the philosophy of widening access to higher education have contributed to the increase in non-traditional students who enter higher education with a varied spectrum of educational qualifications (Scottish Government 2008). This changed student profile have led to some academic staff raising concerns in relation to students' academic performance and their ability to successfully undertake the academic demands placed on them throughout their nursing degree (McCarey et al. 2007).

Cree et al. (2009) carried out a longitudinal study of 45 social work students' experiences of transition from further education to higher education. Cree et al. (2009) report the students found the transition to be particularly challenging and the results indicated that students did not feel as prepared as they had hoped for university study. Students reported that they had not had experience of formal exams or of the different types of assessment they were now undertaking. They also stated they found academic writing and referencing difficult.

Moir (2010, p.3) advocates the purpose of higher education is one of "Transformation rather than Transmission" with increased focus on the student. $\mathrm{He}$ purports that personal values and social experience are now being seen as important graduate attributes compared to the traditional view that focussed on gaining knowledge and understanding. The higher education experience is more than ever about empowering students to engage and take ownership of their learning.

\section{Empowerment / Engagement}

Empowerment is multi-faceted and not just about making sure the students have the knowledge to enter year 2. Empowerment according to Bradbury
Jones et al (2010) involves knowledge and confidence. Bradbury Jones et al (2010) further suggest if knowledge and confidence are addressed then enhancement of self-efficacy will follow. Lowe and Cook (2003) highlighted in their study a substantial minority of students (up to 20\%) were failing to come to terms with the academic and social demands of university life. Hence it is important that students are prepared in every way to address this. Lowe and Cook (2003) suggest that universities need to provide appropriate academic, attitudinal and social preparation but that this "induction" is not seen as a one off event but rather a process involving staff, students and peers.

It is suggested by The Quality Assurance Agency for Scotland, (QAA 2008) that in order to be empowered students must be engaged and feel they have a sense of belonging. This engagement commences with meeting the students informally to advise them about the articulation opportunity and follows through selection, pre module information then the summer module. This engagement encompasses academic, social, personal and professional engagement.

QAA (2008) argue that students who are engaged emotionally, cognitively and behaviourally in their education will have enhanced affiliation with their institution and in turn higher levels of motivation, attendance and persistence. Purnell (2006) argues that first year is the ideal time to set up the infrastructure for student engagement. However if they are entering at year 2 it is imperative that this potential gap is filled. QAA (2008) define empowerment broadly as the student's competency to engage effectively with their studies which involved them becoming independent learners. Part of becoming an independent learner is confidence which was explored by Bloy \& Pillai (2006). They concluded that students need to be given the tools (including confidence and competence) to help them engage The work done by Bloy \& Pillai (2006) provided evidence of the positive benefits of engagement, including enhanced motivation \& increased awareness to seek help when needed.

Learner journeys according to the Scottish Government (2011) have changed and universities must be flexible and adaptable whilst facilitating these journeys so that the learner is not set up to fail. Thus this new innovative learner journey seeks to engage students early and empower them to succeed in higher education. This module provides students with the key strategies to promote empowerment to succeed in their articulation to second year. 


\section{PLE Module}

This stand-alone module allows articulation of a group of HNC students into year 2 of the Undergraduate Nursing programme. It is levelled at Scottish Credit Qualifications Framework (SCQF) level 7 and awarded 20 points. All relevant HNC classes from the partner FE Colleges are given information about the module and the criteria for articulating into year 2 . This allows the students to put themselves forward to be selected. The criteria includes: completion of full $\mathrm{HNC}$ in college, graded unit at mark A or B; completion of 760 hours by the end of the module (NMC, 2010) of which 180 must be completed within the module and at least 450 hours done as part of HNC; completion of UWS selection process; satisfactory health screening and Criminal Check - Protection of Vulnerable groups (PVG).

The FE colleges then collate a short list of students they would support to undertake the module. These students are invited to a personal interview at UWS and if successful are offered a place through the Universities \& Colleges Admissions Service (UCAS).

The number of places on offer is reviewed and agreed with the colleges annually. It is derived by reviewing the last number of cohorts through the year one period and balancing any losses against the number of audited practice experience areas UWS has available. The outcomes for the HNC and the UWS first year are meticulously mapped together (NMC, 2010) to identify any core elements requiring to be covered in the summer module. Meetings take place 3-4 times a year with the colleges, university \& Health Board partners to fully discuss module developments and student's progress.

The module's overall aim is to aid transition into university socially, academically \& professionally. The more specific aims are to facilitate the development of knowledge, skills and professional values within the healthcare environment that will enable students to demonstrate that they have met the requirements for the progression into year 2 of the pre-registration nursing degree programme. The bespoke module includes study days (subjects covered include maternity and paediatric care, mental health issues, personal and professional development and skills teaching), simulated practice and practice experience hours. Students complete a portfolio of evidence over the module. The overall assessment is twofold, clinical assessment (50\%) and reflective portfolio (50\%).

\section{Realities of the module}

The inaugural implementation of the module highlighted several realties. Firstly the students had no financial assistance. Although a fee waiver was put in place no bursary support or expenses for travel costs was available. Secondly the students had to undertake this module over the summer months immediately following their HNC studies. They also had little time off for private work or leisure with their families.

\section{Module Evaluation}

The PLE module commenced July 2012 with 20 students from 9 different FE colleges. 17 completed and 17 evaluated their experience.

The purpose of evaluation is to make judgements about a course / programme and thus improve its effectiveness (Patton, 1987). Gullickson (2000) suggests that evaluation is an integral and inevitable feature of all aspects of education. It is further highlighted by Gullickson (2000) that student evaluations are particularly useful to provide feedback, inform academic growth, enhance School policy and provide public accountability.

In the case of this new bespoke module students were evaluated as were their clinical mentors and the FE College partners involved. This paper highlights the students' evaluations and shows how these link to empowerment.

This module is mapped carefully and specifically designed to support these students in their articulation to second year. The study days provide theoretical knowledge as well as enhancing clinical skills practice. Key issues emerging are confidence, knowledge and preparation. 


\section{Student evaluations - Findings}

\section{Evaluation of UWS - Practice Learning Experience Module}

On a scale of $1-5,1$ being the worst and 5 being the best please answer the following by circling as you feel appropriate

1. This module was useful to me

2

Responses

3

$\%$ of all responses

4

$\begin{array}{ll}4 & 5 \\ 4 & 13 \\ 24 \% & 76 \%\end{array}$

Comments included : "better insight to the university", "Gave me better confidence", "prepared me for university life", "opportunity to learn more skills", "gave me knowledge"

2. This module was informative for me

2

3

$\begin{array}{ll}4 & 5 \\ 8 & 9 \\ 47 \% & 53 \%\end{array}$

Comments included : "lecturers were excellent at giving out information on skills and theory", "allowed me to learn about university life", "gained vital information about the programme",

3. This module helped prepare me for year 2 entry

1

$$
2
$$

$\begin{array}{lll}3 & 4 & 5 \\ 1 & 4 & 12 \\ 6 \% & 24 \% & 70 \%\end{array}$

Comments included: "prepared me for entry to year 2", "I think I have been given all the tools I need to progress effectively to year 2", "the experience of meeting the teaching staff"

4. This module helped prepare me to start at university

$\begin{array}{lllll}1 & 2 & 3 & 4 & 5 \\ & 1 & 5 & 11 \\ & 6 \% & 29 \% & 65 \%\end{array}$

Comments included: "after being told what was expected of me and the support that was given to me by my lecturer I feel I am confident", "it covered aspects of new theory and skills which will help me progress in university", "meeting other students who were acting as buddies was a great relief and provides support and familiar faces", "it gave me a good understanding of academic expectations...meeting with my personal tutor has been a great help as i have begun to build a working relationship with her"

4. Do you feel inspired to succeed after this module?

Yes

NO

$16 \quad 1$ response was in the middle!

$94 \% \quad 6 \%$

Comments included: "I feel motivated to continue and learn more", "the lecturers support has inspired me", "I feel more motivated to achieve" 
Model

Empowering Students

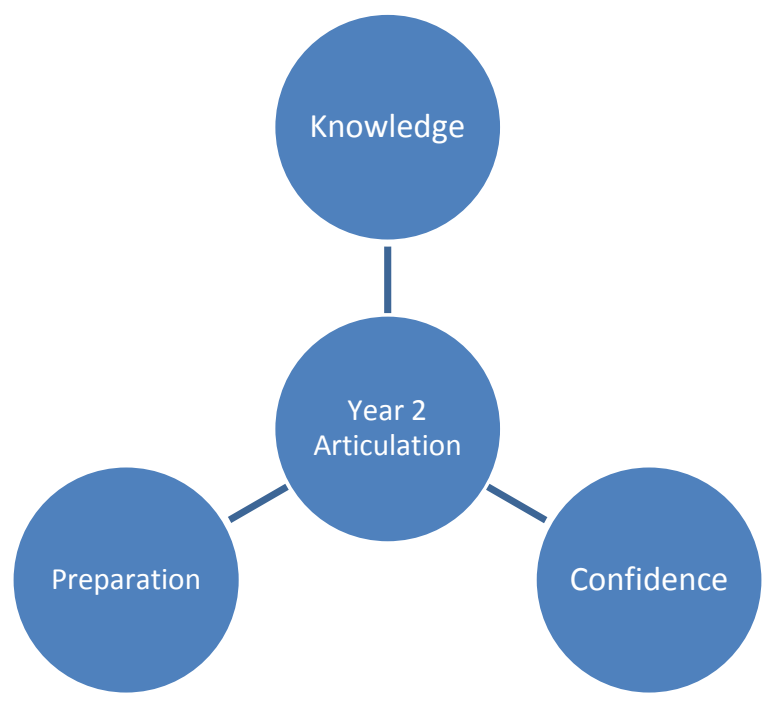

\section{Knowledge}

'I think I have been given all the tools to progress effectively into Second Year'.

'Allowed me to progress my learning and understand what is needed'.

\section{Confidence}

'After being told what was expected of me and the support that was given to me by my lecturers, I feel I am confident to proceed into Second Year'.

'Feel a lot happier going into second year after doing this Module'.

\section{Preparation}

'It covered aspects of new Theory and Skills which will help me progress in Uni and has made me feel prepared to progress'.

'It gave a good understanding of academic expectations'.

\section{Link to empowerment}

The main themes to emerge from the qualitative comments were confidence, knowledge and being prepared. Previous discussion in this paper highlighted the vital role that confidence and knowledge plays in empowering students (Bradbury- Jones et al 2010, Lowe \& Cook 2003, QAA 2008, and Harvey et al 2006). The aspects of transition discussed earlier further elicit the area of being prepared personally, socially, \& academically. Work alluded to by Bloy and Pillai (2006) provided evidence of the positive benefits of engagement and empowerment.

\section{Future of module}

Research has been proposed to follow this first cohort of students and track their progress through the journey to registration and graduation. The team feel this will provide more complete evidence of the support needs to empower students to succeed within university.

The re mapping of all the HNC programmes feeding into UWS year 2 has been successfully completed and proved very helpful to both FE and He partners. UWS have selected the students for the summer 2013 module and they have already had an introductory session in university

\section{Conclusion}

Higher Education ( $\&$ nurse education) has been constantly changing since Robbins aims were set out in 1963. Learner journeys have evolved and UWS has responded by providing this unique opportunity to articulate into a much sought after nursing degree programme. At the heart of all this change are students with individual learning needs. We believe that such students can be, and are empowered through confidence, knowledge and being prepared. Through this journey they are inspired to succeed. 


\section{REFERENCES}

Bloy, S and Pillai, M (2006) Engaging Students as independent and confident learners. Workshop presented at the Higher Education Academy Challenge of student Engagement Conference. University of Nottingham Nottingham.

Bradbury Jones, C, Irvine, F and Sambrook, S (2010) Empowerment of Nursing Students in clinical practice: spheres of influence, Journal of Advanced Nursing vol 66,no 9, pp 2061-2070

Cree, V., Hounsell, J., Christie, H., McCune, V. and Tett,L (2009) "From Further Education to Higher Education: Social Work Students' Experiences of Transition to an Ancient, ResearchLed University", Social Work Education, vol. 28, no. 8 , pp. $887-901$.

Fleming, S. \& McKee, G. (2005) "The mature student question", Nurse Education Today, vol. 25, no. 3 , pp. $230-237$

Gallacher, J. (2006) Blurring the Boundaries or creating diversity? The contribution of Further Education Colleges to Higher Education in Scotland, Journal of Further and Higher Education, vol. 30, no. 1 pp.43-58.

Gullickson, A R (2000) The need for student evaluation standards, Prepared by the Joint Committee for educational evaluation. Joint Committee on standards for educational evaluation (1994) Thousand Oaks , C A Sage

Haigh, J. (2004) "Information technology in health professional education: why IT matters", Nurse Education Today, Vol. 24, no. 7, pp. 547-552.

Harvey, L., Drew, S. and Smith, M. (2006) The first-year experience: a review of literature for the Higher Education Academy, Higher Education Academy: York

Lowe, H and Cook, A (2003) Mind the Gap : are students prepared for higher education? Journal of Further \& Higher Education vol 27, no 1, pp 5376

McCarey, M., Barr, T. and Rattray, J. (2007) "Predictors of academic performance in a cohort of pre-registration nursing students", Nurse Education Today, Vol. 27, no. 4, pp. 357-364.

McInnis, C., James, R. and Hartley, R. (2000) Trends in the first year experience. AGPS: Canberra
Moir, J. (2010) The First Year - Back to the future [online]. Available from: http://www.enhancementthemes.ac.uk/documents/ G21C/FYBacktothefuture.pdf [Accessed 20 March, 2011]

Nursing \& Midwifery Council (2004) Standards of proficiency for pre-registration nursing education, NMC: London

Nursing \& Midwifery Council (2010) Standards of proficiency for pre-registration nursing education, NMC: London

Patton, M Q (1987) Research Evaluation Methods. Thousand Oaks C A Sage

Peyrovi, H., Yadavar-Nikravesh, M., Oskouie, S. F. and Berterö, C. (2005) "Iranian student nurses' experiences of clinical placement", International Nursing Review, vol. 52, no. 2, pp. 134-141

Purnell, S (2006) Transition \& Engagement. Workshop presented at the Higher Education Academy Challenge of Student Engagement conference. University of Nottingham. Nottingham

Scottish Credit and Qualifications Framework (2001) An Introduction to the Scottish Credit and Qualifications Framework, SCQF: Edinburgh.

Scottish Executive (1999) Opportunities For Everyone: A Strategic Framework for Scottish Further Education, HMSO: Edinburgh.

Scottish Executive (2003) Life Through Learning Through Life: The Lifelong Learning Strategy for Scotland, Scottish Executive: Edinburgh.

Scottish Funding Council (2011) Flexible entry into Higher Education, [Online] http://www.sfc.ac.uk/web/FILES/ReportsandPublic ations/Flexible entry into_higher_education.pdf [Accessed 18th March 2013]

Scottish Government Statistics (2008) High Level Summary of Statistics: Lifelong Learning, Scottish Government Statistics: Edinburgh.

Scottish Government (2011) Putting Learners at the centre : delivering our ambitions for post 16 education, Scottish Government, Edinburgh

Steele, R., Lauder, W., Caperchione, C. and Anastasi, J. (2005) An exploratory study of the concerns of mature access to nursing students and the coping strategies used to manage these adverse experiences", Nurse Education Today, vol. 25, no. 7, pp. 573-581 
The Quality Assurance Agency for Higher Education (QAA) (2008) Quality Enhancement Themes. The First Year Experience, QAA, Mansfield

The Robbins Report on Higher Education (1963) Report of the Committee appointed by the Prime Minister under the Chairmanship of Lord Robbins, London

Thomas, L. and Hixenbaugh, P. (2006) Personal Tutoring in HE, Trentham Books: London.

Tinto, V. (1987) Leaving College. University of Chicago Press: Chicago Cited in: Whittaker, R. (2008) Quality Enhancement Themes: The First Year Experience Transition to and during the first year, QAA Scotland: Glasgow.

UKCC (1986) Project 2000 - A new preparation for practice, UKCC: London
University of the West of Scotland (UWS) (2008) Looking Forward, Strategic Plan 2008-2015, UWS

University of the West of Scotland (2009) South West Articulation Hub (SWAH) Forward Plan 2008-2013, UWS

Whittaker, R. (2008) Quality Enhancement Themes: The First Year Experience Transition to and during the first year, QAA Scotland: Glasgow.

Woodfield, R. (2002) Student Perceptions of the First Year Experience of University 2000/2001 Results from a Qualitative Email Survey. Falmer; University of Sussex.

Yorke, M.and Longden, B. (2007) The first-year experience of higher education in the UK, Higher Education Academy: York 